\title{
Relationship between pre-partum relaxin concentrations and farrowing intervals in the pig
}

\author{
D. C. Wathes, G. J. King*, D. G. Porter† and C. M. Wathesł \\ Department of Anatomy, The Medical School, Bristol BS8 1TD, UK; \\ * Department of Animal \& Poultry Science, and + Department of Biomedical Sciences, \\ Ontario Veterinary College, University of Guelph, Guelph, Ontario N1G 2W1, Canada; and \\ $\ddagger$ Department of Animal Husbandry, University of Bristol, Langford, Bristol BS18 $7 D U, U K$
}

\begin{abstract}
Summary. Gilts were treated on Day 112 of gestation with saline or a prostaglandin (PG) $\mathrm{F}-2 \alpha$ analogue. In control gilts there was a rise in the relaxin concentration from $48 \mathrm{~h}$ before the onset of delivery, peaking between 12 and $28 \mathrm{~h}$ pre partum followed by a steep fall. The relaxin concentrations at each 1-h time interval were analysed in relation to the farrowing interval for each gilt using correlation analysis. There was a significant (at least $P<0.05$ ) positive correlation between the relaxin concentration and the farrowing interval at every time period from 14 to $2 \mathrm{~h}$ before delivery. In contrast there was little relationship between concentrations of progesterone, oestrone and oestradiol- $17 \beta$ and farrowing intervals. The gilts treated with PGF- $2 \alpha$ analogues had steroid profiles indistinguishable from those in controls but differing relaxin secretion patterns. Relaxin concentrations peaked at $1-2 \mathrm{~h}$ after PGF-2 $\alpha$ injection and this was followed by a second smaller increase closer to the time of delivery in 7 out of 12 gilts. The 'two-peak' gilts had significantly higher relaxin concentrations at farrowing and took significantly longer to farrow than did the 'one-peak' gilts $(P<0.005)$. These results suggest that high relaxin concentrations during the last $14 \mathrm{~h}$ before the onset of parturition are associated with increased farrowing times, but are not associated with any increase in neonatal mortality.
\end{abstract}

Keywords: relaxin; parturition/farrowing; pig

\section{Introduction}

Concentrations of relaxin in the peripheral blood of pigs remain low throughout most of gestation, but rise slowly from Day 100, culminating in a major surge peaking about $18 \mathrm{~h}$ before the start of delivery, and declining before parturition has begun (Sherwood et al., 1975, 1981; Sherwood, 1982). Relaxin appears to be necessary for normal deliveries since ovariectomized pigs or those with CL excision maintained on progesterone and induced to farrow by withdrawal of progesterone have prolonged deliveries and a high incidence of stillbirths, which are prevented by replacement of relaxin (Kertiles \& Anderson, 1979; Nara et al., 1981, 1982). Relaxin inhibits myometrial activity in the pig (Porter \& Watts, 1986; Watts et al., 1988) and it has been suggested (Porter, 1979) that in the normal animal the relaxin surge could prevent premature uterine contractions during the period of progesterone withdrawal. Moreover, there is good evidence that relaxin increases cervical distensibility (for review, see Porter, 1981) and further work in the rat has indicated that relaxin can act centrally to inhibit oxytocin release (Summerlee et al., 1984; Jones \& Summerlee, 1986a). These studies suggest that relaxin may play a complex role at parturition. The surge may be necessary to achieve cervical dilatation, but high concentrations of relaxin thereafter could inhibit the process of delivery. It was therefore of interest to determine whether a relationship exists between plasma 
relaxin concentrations and farrowing intervals in pigs. These studies were performed in control animals and in pigs induced to farrow with analogues of prostaglandin (PG) F-2 $\alpha$, as this treatment results in an altered pattern of relaxin secretion (Sherwood et al., 1976).

\section{Materials and Methods}

Animals. Eighteen Large White $\times$ Landrace gilts were cannulated via the ear veins on Day 108 of gestation, placed in farrowing crates and allocated at random to control or parturition-induced groups. The control gilts $(\mathrm{N}=6)$ received $2 \mathrm{ml}$ saline $(0.154 \mathrm{M})$ i.m. on Day 112 . The induced gilts $(\mathrm{N}=6$ per treatment) received either $10 \mathrm{mg}$ dinoprost tromethamine (Lutalyse: Upjohn Co., Kalamazoo, MI, USA) or $175 \mu \mathrm{g}$ cloprostenol (Estrumate: Coopers Ltd, Willowdale, Ontario, Canada) administered i.m. on Day 112. Heparinized blood samples were collected hourly from $2 \mathrm{~h}$ before injection until $3 \mathrm{~h}$ after the start of farrowing. The blood was chilled and centrifuged and the plasma was stored at $-20^{\circ} \mathrm{C}$. The gilts were observed continuously for signs of parturition. The time of birth of each piglet was recorded in the absence of any obstetrical assistance.

Radioimmunoassays (RIAs). Previously validated RIAs were used for the measurement of relaxin (every $\mathrm{l} h$ ) and progesterone, oestrone and oestradiol-17 $\beta$ (every $2 \mathrm{~h}$ ).

Relaxin RIA. Assays were performed as described previously (Taverne et al., 1982) at dilutions of 1:5 and 1:50 for each sample. Assay sensitivity was $32 \mathrm{pg} /$ tube, and the intra- and inter-assay coefficients of variation were $2.5 \%$ and $21 \cdot 5 \%$ respectively.

Progesterone RIA. This was performed as described by King et al. (1985), using $10 \mu l$ plasma samples. The extraction efficiency was $90 \%$, the assay sensitivity was $153 \mathrm{pg}$ and the intra- and inter-assay coefficients of variation were $8.8 \%$ and $7.5 \%$, respectively.

Oestrogen RIAs. These were performed as described by Robertson et al. (1985). Plasma samples (100 $\mu$ l) were extracted and the two steroids separated by celite column chromatography. The extraction efficiencies were $90 \%$ for oestradiol- $17 \beta$ and $80-85 \%$ for oestrone and the assay sensitivities were $2.1 \mathrm{pg}$ and $1.9 \mathrm{pg}$ for the two steroids respectively. The intra- and inter-assay coefficients of variation were $9.2 \%$ and $12.5 \%$ for oestradiol- $17 \beta$ and $7.2 \%$ and $13 \cdot 4 \%$ for oestrone.

Statistical analysis. The farrowing interval (FI) for each pig was calculated as the total time taken to deliver all the piglets divided by the litter size. Time zero was defined as the collection period before the birth of the first piglet. The relationship between the farrowing interval and the hormone variables (e.g. time of relaxin peak height) and the hormone concentrations at each 1 - or 2-h interval preceding the onset of parturition was examined using linear correlation analysis. An initial comparison between the relaxin profiles of the two groups given prostaglandin treatments was made using ANOVA. This showed no significant differences over time and the two PG-treatment groups were therefore combined for subsequent analysis. All variates followed a normal distribution. Separate correlation analyses were made for the control and PG-treated groups. Comparisons between parturition characteristics were made using a Mann-Whitney or Student's $t$ test.

\section{Results}

The endocrine changes in response to treatment have been reported in detail in a separate paper (King \& Wathes, 1989). In brief, parturition occurred significantly earlier after PG treatment, with injection to farrowing intervals of $67 \pm 14,29 \pm 3$ and $24 \pm 1 \mathrm{~h}$ for the control, dinoprost and cloprostenol groups respectively (mean \pm s.e.m., $N=6$ per group). The progesterone, oestrone and oestradiol-17 $\beta$ profiles before delivery were similar in all three groups, with progesterone concentrations falling in the last $24 \mathrm{~h}$ and little change in oestrogen values during this period. However, the relaxin profiles clearly differed among groups. In the control gilts there was a gradual elevation in the circulating concentration from $48 \mathrm{~h}$ before delivery with an initial minor peak about $30 \mathrm{~h}$ pre partum and a major peak between 12 and $28 \mathrm{~h}$ pre partum after which titres fell steeply. Changes in the 2 PG-treatment groups were similar, with a relaxin peak occurring within about $1 \mathrm{~h}$ of treatment, at an average time of $24.8 \mathrm{~h}$ before the start of delivery. In 7 out of 12 animals this peak was followed by a second smaller one. The results presented here examine the relationship between these endocrine changes and the duration of delivery in individual gilts. All piglets in all groups were born alive. 


\section{Control gilts}

These 6 animals produced $9.5 \pm 0.4$ piglets in $3.4 \pm 0.8 \mathrm{~h}$ (range $1.3-5.6 \mathrm{~h}$ ) leading to a mean farrowing interval of $0.36 \pm 0.08 \mathrm{~h}$ (range $0.12-0.56 \mathrm{~h}$ ). Gilts with higher relaxin concentrations in the last $24 \mathrm{~h}$ before delivery took longer to farrow (Fig. 1). The length of the farrowing interval for each pig was not related to the total number of piglets each animal produced, or to the interval from saline injection to parturition, but there was a significant positive correlation between the height of the relaxin peak and the farrowing interval $(P<0.05)$ and a significant negative correlation between the time interval from peak height to farrowing and the farrowing interval $(P<0.05)$. To examine this relationship in more detail the relaxin concentrations at each $1-\mathrm{h}$ time interval leading up to the initiation of delivery were correlated with the farrowing interval (Fig. 2). There was a significant positive correlation between these two variables at each individual time period from 14 to $2 \mathrm{~h}$ before delivery. During this period, the minimum value of the correlation coefficient, $r$, always exceeded the critical value of $0.81(P<0.05)$, which implies that a linear association between the relaxin concentration and the farrowing interval accounted for a minimum of $66 \%$ of the total variation in the data.

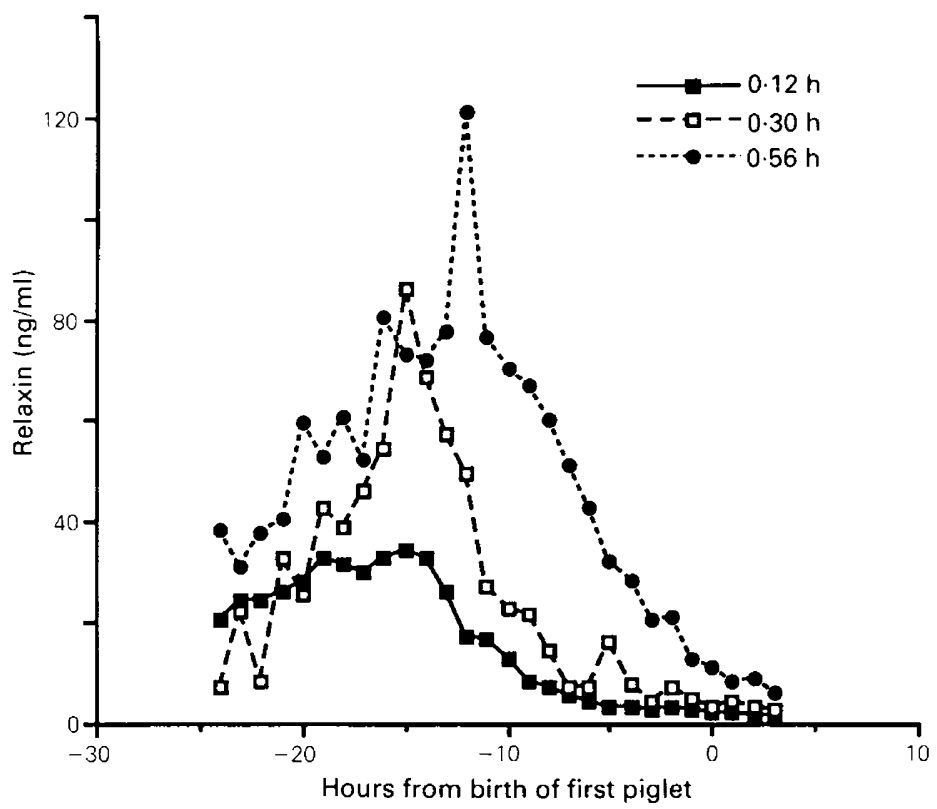

Fig. 1. Plasma relaxin profiles in the last $24 \mathrm{~h}$ before the onset of parturition in 3 control gilts with different farrowing intervals (see text) as shown.

In contrast to this consistent correlation with relaxin, there was little relationship between steroid concentrations and delivery times. The time from the first decline in progesterone concentrations to parturition was not related to the farrowing interval. Looking at individual 1-h time periods for progesterone there was one significant $(P<0.05)$ negative correlation at $-12 \mathrm{~h}$ (Fig. 2). Oestrone concentrations showed a significant positive correlation at -6 and $-4 \mathrm{~h}$ whereas the oestradiol-17 $\beta$ concentrations were not related to the farrowing interval (Fig. 3). The oestrogen: progesterone ratios were also examined. There was a significant correlation $(P<0.05)$ between both the oestrone: and oestradiol:progesterone ratios at $-20 \mathrm{~h}$, and the oestradiol:progesterone ratio was also correlated at $-24 \mathrm{~h}(P<0.05$, data not shown). Therefore, these significant correlations between farrowing interval and steroid concentrations only occurred sporadically ( 5 occasions out of 84 correlations, $5.9 \%$ ) and may well have arisen by chance. 


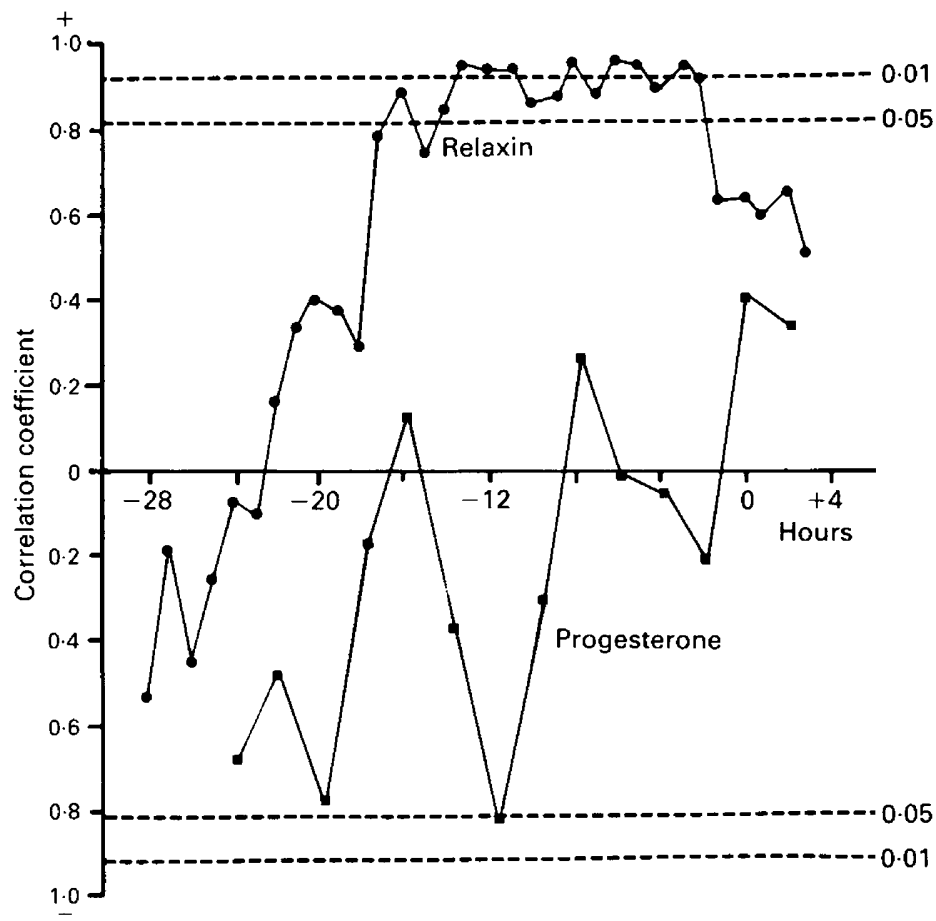

Fig. 2. Linear correlation analysis between the relaxin plasma concentrations and farrowing intervals in 6 control gilts calculated at each $1-\mathrm{h}$ time interval (for relaxin) and 2-h time interval (for progesterone) from $28 \mathrm{~h}$ before the start of parturition (time 0$)$ until $3 \mathrm{~h}$ after. Broken lines show critical levels of significance $(P<0.05$ and $P<0 \cdot 01)$.

\section{Prostaglandin-treated gilts}

The $12 \mathrm{PG}$-treated gilts produced $8.5 \pm 0.65$ piglets in $3.0 \pm 0.61 \mathrm{~h}$ (range $0.56-6.88$ ) leading to a mean farrowing interval of $0.35 \pm 0.07 \mathrm{~h}$ (range $0.08-0.77$ ). None of these values differed significantly from those in the control group (Student's $t$ test). There was a significant $(P<0 \cdot 01)$ positive correlation between the interval from PG injection to farrowing and the farrowing interval but, in contrast to the control gilts, there was no correlation between either the height of the relaxin peak, or the interval from the relaxin peak to the onset of farrowing, and the farrowing interval. Neither was there a significant correlation between relaxin concentrations at different 1 -h time periods and farrowing intervals. However, an examination of individual relaxin profiles (Fig. 4) revealed wide differences in response between animals, with $7 / 12$ having a second smaller relaxin peak between the time of treatment and the onset of parturition. This meant that relaxin concentrations were not necessarily following the same trend (increasing or decreasing) among different animals at the same time relative to farrowing. The gilts were therefore divided into two subgroups for further analysis, based on either one or two relaxin peaks. The 'two-peak' animals had a significantly higher relaxin concentration at the onset of farrowing and took significantly longer to farrow (Table 1).

Steroid concentrations were also examined in relation to farrowing intervals. The changes in steroid concentrations with time did not differ between control and PG-treated pigs. The time from the start of the progesterone decline to farrowing was correlated with the farrowing interval $(P<0.05)$. However, there was no relationship between progesterone or oestradiol-17 $\beta$ concentrations at individual time periods and farrowing intervals, although oestrone concentrations showed a significant positive correlation $(P<0.05)$ at $-2 \mathrm{~h}$ only. 


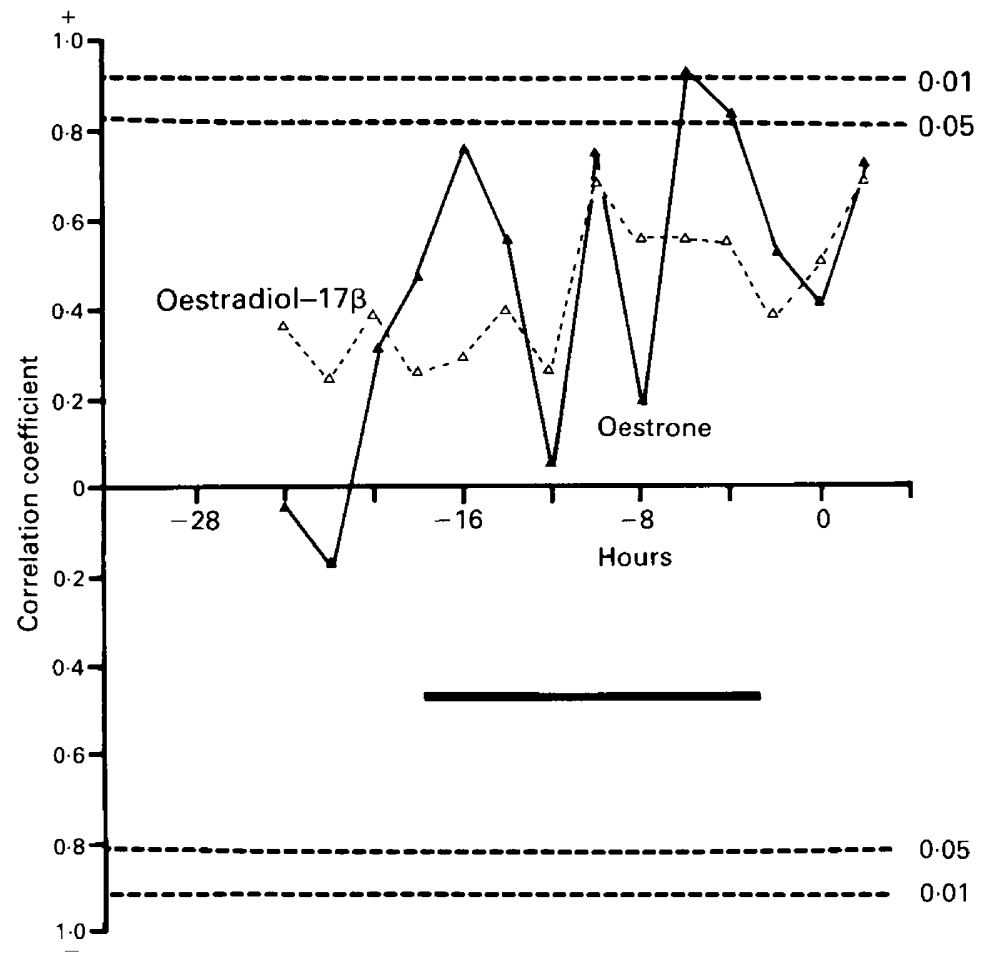

Fig. 3. Linear correlation analysis between the oestrone $(\Delta-\Delta)$ and oestradiol-17 $\mathbf{\Delta}(\triangle---\triangle)$ concentrations and farrowing intervals in 6 control gilts, calculated at each 2 -h time interval from $28 \mathrm{~h}$ before the start of parturition (time 0 ) until $2 \mathrm{~h}$ after. Broken lines show critical levels of significance $(P<0.05$ and $P<0.01)$. The solid bar indicates the period throughout which there was a significant correlation between the relaxin concentration and the farrowing interval.

\section{Discussion}

Analysis of the hormone profiles from the control gilts has established a clear positive association between the circulating relaxin concentrations in the period from 14 to $2 \mathrm{~h}$ before delivery and the time taken to deliver the piglets. Although the mechanism by which relaxin may produce this effect was not examined in the present study, it is reasonable to conclude that it may have been attributable to at least two of the known actions of this hormone. Relaxin inhibits the myometrium in the pig (Porter \& Watts, 1986) and it has been shown that in the late pregnant mini-pig the evolution of electromyographic activity in the uterus does not begin until plasma relaxin concentrations decline, despite increasing concentrations of PGFM (Watts et al., 1988). Also, it has been shown that relaxin inhibits the release of oxytocin from the posterior pituitary in the rat (Summerlee et al., 1984) and that infusion of relaxin into rats during the perinatal period prolongs gestation and increases the birth interval significantly while reducing oxytocin output (Jones \& Summerlee, 1986a, b). It is known (Forsling et al., 1979; Taverne et al., 1979) that oxytocin titres increase slightly in the last $9 \mathrm{~h}$ before delivery in sows and that this increase is associated with a transformation of uterine electromyographic activity from an irregular to a regular pattern. A further increase in oxytocin output accompanies the expulsion of the piglets. If relaxin exerts a similar effect in the pregnant sow as has been reported for the rat, then the correlation revealed in the present study between relaxin titres after the surge and the birth interval may be due both to the myometrial inhibitory and the oxytocin suppressive actions of the hormone. 


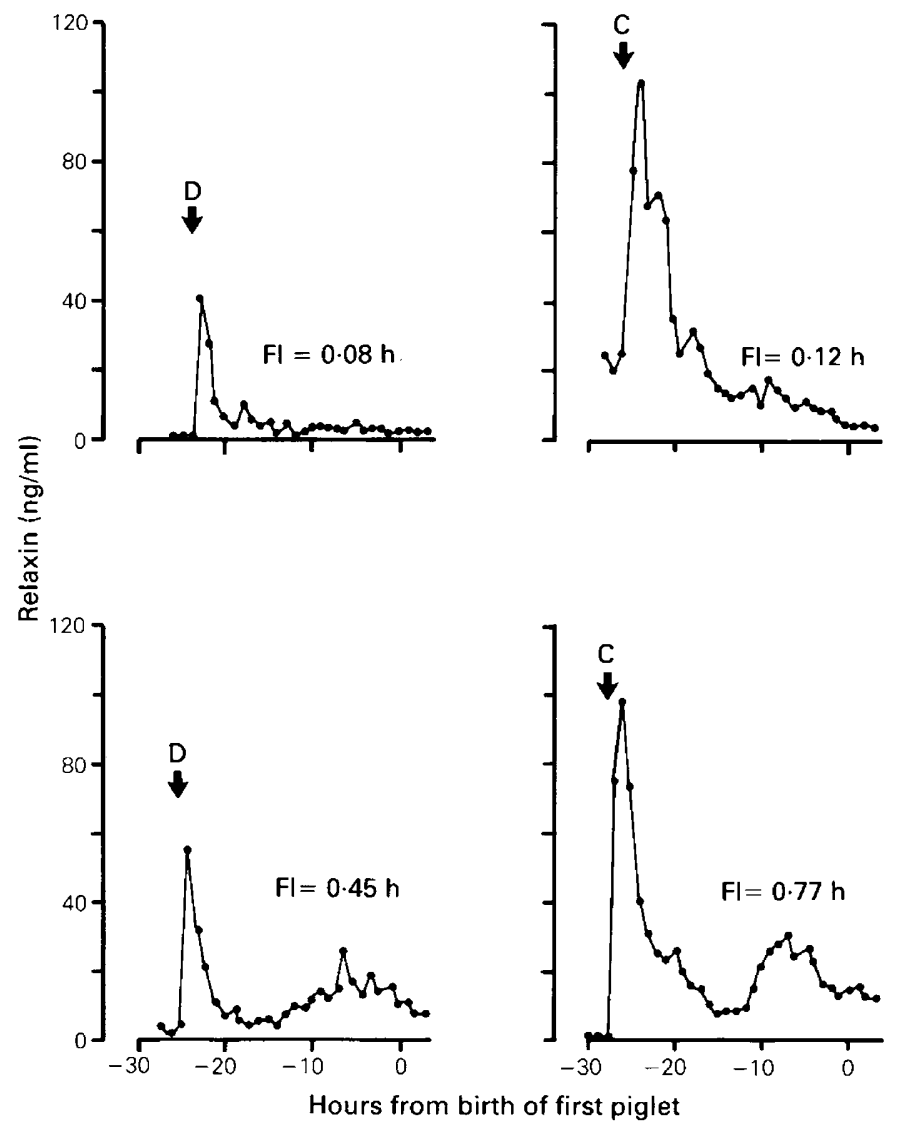

Fig. 4. Relaxin profiles in 4 individual gilts given dinoprost (D) or cloprostenol (C) on Day 112 of gestation. The farrowing interval (FI) for each animal is shown.

Table 1. Parturition characteristics for prostaglandin-treated gilts

\begin{tabular}{lccc}
\hline & 1 relaxin peak & 2 relaxin peaks & Significance $\dagger$ \\
\hline $\begin{array}{l}\text { No. of gilts } \\
\begin{array}{l}\text { Time from treatment to } \\
\text { farrowing (h) }\end{array}\end{array}$ & 5 & 7 & \\
& $23.4 \pm 1.3$ & $\begin{array}{c}27.2 \pm 0.8 \\
(\mathrm{~N}=6)^{*}\end{array}$ & $P<0.005$ \\
$\begin{array}{l}\text { Median no. of piglets born } \\
\text { Relaxin at onset of } \\
\text { farrowing (ng/ml) }\end{array}$ & 8 & 10 & $\mathrm{NS}$ \\
Farrowing interval (h) & $6.3 \pm 1.9$ & $17.2 \pm 2.7$ & $P<0.005$ \\
\hline
\end{tabular}

*Excludes one gilt which did not respond to treatment by a fall in progesterone concentration and farrowed $41 \mathrm{~h}$ later.

†Analysed by Student's $t$ test, or Mann-Whitney test as appropriate.

Watts et al. (1988) reported that infusion of relaxin into ovariectomized mini-pigs abolished myometrial electromyographic activity, although not indefinitely, since activity eventually returned despite continued infusion of the hormone. Similarly, Jones \& Summerlee (1986b) found that some 
of their rats which received continuous infusions of relaxin delivered before the infusions were completed, albeit later than did saline-treated controls. Both of these findings are consistent with the observations of the present work that pigs, controls and PG-analogue treated, delivered with widely different plasma relaxin titres. Moreover, although the birth intervals were longer in pigs with higher post-peak relaxin titres and in rats receiving relaxin infusions (Jones \& Summerlee, 1986b), the neonatal mortality was not increased in either group. This may reflect another action of relaxin, softening of the cervix (see Porter, 1981; Sherwood, 1982), thus reducing the mortality associated with even the protracted parturitions.

Treatment of the gilts with a single dose of a PGF- $2 \alpha$ analogue led to an immediate relaxin surge, but the plasma profile of relaxin during the last $48 \mathrm{~h}$ before delivery differed significantly from that in the control gilts. These data are similar to those of Sherwood et al. (1976) in that the majority of treated animals experienced a second period of elevated relaxin concentrations before giving birth. In view of these differences in the secretion pattern between animals it is not surprising that the correlations between relaxin concentrations at a particular time and the farrowing intervals were less consistent than in control pigs. For this reason a further analysis was performed to compare the characteristics of parturition between 'one-peak' and 'two-peak' animals. It was apparent that animals experiencing a second peak took longer to go into labour and also had longer farrowing intervals.

It is well established that the release patterns of a variety of other hormones alter significantly at term and that these too play a role in the initiation of labour (reviewed by First $e t$ al., 1982; Taverne, 1982; Porter, 1989). PGF-2 $\alpha$ is clearly important but was not measured in the present study. However, we were able to examine the relationship between the changes in three steroid hormones and the farrowing intervals. There was little correlation with the progesterone concentrations which started to fall about $36 \mathrm{~h}$ before the start of parturition. This is in agreement with the study of Watts et al. (1988) who concluded that the lack of correlation was attributable to the rising relaxin titres replacing progesterone as the principal myometrial inhibitor at this time. Taverne et al. (1979) also reported that changes in electrical activity of the uterus did not start until some time after progesterone concentrations had fallen and oestrogen concentrations had risen. In the present study there was no relationship between farrowing intervals and the concentration of oestradiol-17 $\beta$, but there was a slight indication that high concentrations of oestrone in the last $6 \mathrm{~h}$ before parturition were associated with slower deliveries. At present the role of oestrogen in regulating myometrial activity in the sow is unclear. Oestrogen concentrations rise gradually in late pregnancy and are generally thought to be stimulatory upon the uterus via an action on PGF- $2 \alpha$ release. However, treatment of late pregnant pigs with large doses of exogenous oestrogen in three separate studies was unable to induce parturition (see First et al., 1982). In ovariectomized, progesterone pre-treated, non-pregnant sows a single injection of oestradiol-17 $\beta$ induces a cyclic pattern of myometrial electromyographic activity for up to 2 days in which periods with regular, well-propagated bursts alternate with periods of quiescence (Taverne, 1982).

In conclusion, our data support the general hypothesis that relaxin can regulate both the timing and speed of parturition. This may be achieved both by a direct inhibition of electrical activity in the myometrium and by preventing the central release of oxytocin. Therefore a reduction in circulating relaxin concentrations would appear to be a necessary prerequisite for normal delivery. This may be an important point to consider in designing treatments in which relaxin is used for its beneficial role in cervical ripening.

We thank Mrs A. Bufton, Miss A. Moffat, D. Bellissimo and R. Rajamahendran for skilled technical assistance; and Miss E. K. Wheatley for typing the manuscript. The work was supported by the Ontario Ministry of Agriculture and Food (Canada), the Natural Science \& Engineering Research Council (Canada), the MRC (UK), AFRC (UK) and the Wellcome Trust (UK). 


\section{References}

First, N.L., Lohse, J.K. \& Nara, B.S. (1982) The endocrine control of parturition. In Control of Pig Reproduction, pp. 311-342. Eds D. J. A. Cole \& G. R. Foxcroft. Butterworths, London.

Forsling, M.L., Taverne, M.A.M., Parvizi, N., Elsaesser, F., Smidt, D. \& Ellendorf, F. (1979) Plasma oxytocin and steroid concentrations during late pregnancy, parturition and lactation in the miniature pig. $J$. Endocr. 82, 61-69.

Jones, S.A. \& Summerlee, A.J.S. (1986a) Relaxin acts centrally to inhibit oxytocin release during parturition: an effect that is reversed by naloxone. J. Endocr. 111, 99-102.

Jones, S.A., \& Summerlee, A.J.S. (1986b) Effects of porcine relaxin on the length of gestation and duration of parturition in the rat. J. Endocr. 109, 85-88.

Kertiles, L.P. \& Anderson, L.L. (1979) Effect of relaxin on cervical dilatation, parturition and lactation in the pig. Biol. Reprod. 21, 57-68.

King, G.J. \& Wathes, D.C. (1989) Relaxin, progesterone and estrogen profiles in sow plasma during natural and induced parturitions. Anim. Reprod. Sci. 20, (in press).

King, G.J., Walton, J.S. \& Bellissimo, D.J. (1985) Anestrus in pigs: confirmation by a solid phase RIA for progesterone and subsequent response to treatment. Can. vet. J. 26, 2-6.

Nara, B.S., Darmadja, D. \& First, N.L. (1981) Effect of removal of follicles, corpora lutea or ovaries on maintenance of pregnancy in swine. J. Anim. Sci. 52, 794-801.

Nara, B.S. Welle, F.A., Rutherford, J.E., Sherwood, O.D. \& First, N.L. (1982) Effect of relaxin on parturition and frequency of live births in pigs. $J$. Reprod. Fert. 66, 359-365.

Porter, D.G. (1979) Relaxin: old hormone, new prospect. In Reviews of Reproductive Biology, vol. 1, pp. 1-57. Ed. C. A. Finn. Clarendon Press, Oxford.

Porter, D.G. (1981) Relaxin and cervical softening. In The Cervix in Pregnancy and Labour, pp. 85-99. Eds A. M. Anderson \& D. A. Elwood. Churchill Livingstone, London.

Porter, D.G. (1989) Parturition. In World Animal Science, Subseries B: Animal Reproduction, Vol. 14, ch. 10. Ed. G. J. King (in press). Elsevier, Amsterdam.

Porter, D.G. \& Watts, A. (1986) Relaxin and progesterone are myometrial inhibitors in the ovariectomized non-pregnant mini-pig. J. Reprod. Fert. 76, 205-213.
Robertson, H.A., Dwyer, R.J. \& King, G.J. (1985) Oestrogen in fetal and maternal fluids throughout pregnancy in the pig and comparison with the ewe and cow. J. Endocr. 106, 355-360.

Sherwood, O.D. (1982) Relaxin at parturition in the pig. In Control of Pig Reproduction, pp. 343-376. Eds D. J. A. Cole \& G. R. Foxcroft. Butterworths, London.

Sherwood, O.D., Chang, C.C., BeVier, G.W. \& Dziuk, P.J. (1975) Radioimmunoassay of plasma relaxin levels throughout pregnancy and at parturition in the pig. Endocrinology 97, 834-837.

Sherwood, O.D., Chang, C.C., BeVier, G.W., Diehl, J.R. \& Dziuk, P.J. (1976) Relaxin concentrations in pig plasma following the administration of prostaglandin $\mathrm{F}_{2}$ during late pregnancy. Endocrinology 98, 875-879.

Sherwood, O.D., Nara, B.S., Welk, F.A., First, N.L. \& Rutherford, J.E. (1981) Relaxin levels in the maternal plasma of pigs before, during and after parturition and before, during and after suckling. Biol. Reprod. 25, 65-71.

Summerlee, A.J.S., O'Byrne, K.T., Paisley, A.C., Breeze, M.F. \& Porter, D.G. (1984) Relaxin affects the central control of oxytocin release. Nature, Lond. 309, 372-374.

Taverne, M.A.M. (1982) Myometrial activity during pregnancy and parturition in the pig. In Control of Pig Reproduction, pp. 419-436. Eds D. J. A. Cole \& G. R. Foxcroft. Butterworths, London.

Taverne, M.A.M., Naaktgeboren, C., Elsaesser, F., Forsling, M.L., Van der Weyden, G.C., Ellendorff, F. \& Smidt, D. (1979) Myometrial activity and plasma concentrations of progesterone, estrogens and oxytocin during late pregnancy and parturition in the miniature pig. Biol. Reprod. 21, 1125-1134.

Taverne, M., Bevers, M., Bradshaw, J.M.C., Dieleman, S.J., Willemse, A.H. \& Porter, D.G. (1982) Plasma concentrations of prolactin, progesterone, relaxin and oestradiol-17 $\beta$ in sows treated with progesterone, bromocriptine or indomethacin during late pregnancy. J. Reprod. Fert. 65, 85-96.

Watts, A.D., Flint, A.P.F., Foxcroft, G.R. \& Porter, D.G. (1988) Plasma steroid, relaxin and dihydro-ketoprostaglandin F-2 $\alpha$ changes in the minipig in relation to myometrial electrical and mechanical activity and in the pre-partum period. J. Reprod. Fert. 83, 553-564.

Received 1 March 1989 